Technological University Dublin

DÜBLIN

ARROW@TU Dublin

Articles

Crest: Centre for Research in Engineering

Surface Technology

2012-10-14

\title{
Nitrogen and Copper Doped Solar Light Active TiO2 \\ Photocatalysts For Water Decontamination
}

\author{
Mike Fisher \\ Royal College of Surgeons in Ireland \\ Donal Keane \\ Technological University Dublin, donal.keane@tudublin.ie \\ Pilar Fernandez-Ibanez \\ Plataforma Solar de Almeiria
}

See next page for additional authors

Follow this and additional works at: https://arrow.tudublin.ie/cenresart

Part of the Environmental Chemistry Commons, and the Inorganic Chemistry Commons

\section{Recommended Citation \\ Fisher, M. et al. (2012) Nitrogen and copper doped solar light active TiO2 photocatalysts for water decontamination. Applied Catalysis B: Environmental, Volumes 130-131, 7 February 2013, pp. 8-13 doi:10.1016/j.apcatb.2012.10.013}

This Article is brought to you for free and open access by the Crest: Centre for Research in Engineering Surface Technology at ARROW@TU Dublin. It has been accepted for inclusion in Articles by an authorized administrator of ARROW@TU Dublin. For more information, please contact arrow.admin@tudublin.ie, aisling.coyne@tudublin.ie,gerard.connolly@tudublin.ie. Funder: El 


\section{Authors}

Mike Fisher, Donal Keane, Pilar Fernandez-Ibanez, John Colreavy, Stephen HInder, Kevin McGuigan, and Suresh Pillai 


\section{Accepted Manuscript}

Title: Nitrogen and Copper doped solar light active $\mathrm{TiO}_{2}$

photocatalysts for water decontamination

Authors: Mike B. Fisher, Donal A. Keane, Pilar

Fernández-Ibáñez, John Colreavy, Steven J. Hinder, Kevin G.

McGuigan, Suresh C. Pillai

PII:

S0926-3373(12)00481-X

DOI: doi:10.1016/j.apcatb.2012.10.013

Reference:

APCATB 12294

To appear in:

Applied Catalysis B: Environmental

Received date:

30-7-2012

Revised date:

9-10-2012

Accepted date:

$14-10-2012$

Please cite this article as: M.B. Fisher, D.A. Keane, P. Fernández-Ibáñez, J. Colreavy, S.J. Hinder, K.G. McGuigan, S.C. Pillai, Nitrogen and Copper doped solar light active $\mathrm{TiO}_{2}$ photocatalysts for water decontamination, Applied Catalysis B, Environmental (2010), doi:10.1016/j.apcatb.2012.10.013

This is a PDF file of an unedited manuscript that has been accepted for publication. As a service to our customers we are providing this early version of the manuscript. The manuscript will undergo copyediting, typesetting, and review of the resulting proof before it is published in its final form. Please note that during the production process errors may be discovered which could affect the content, and all legal disclaimers that apply to the journal pertain. 
Nitrogen and Copper doped solar light active $\mathrm{TiO}_{2}$ photocatalysts for water decontamination

Mike B. Fisher, ${ }^{1 \dagger}$ Donal A. Keane, ${ }^{2 \dagger}$ Pilar Fernández-Ibáñez, ${ }^{3}$ John Colreavy, ${ }^{2}$ Steven J. Hinder, ${ }^{4}$ Kevin G. McGuigan, ${ }^{1^{*}}$ Suresh C. Pillai ${ }^{2^{\star}}$

${ }^{1}$ Department of Physiology \& Medical Physics, Royal College of Surgeons in Ireland, 123 St Stephens Green, Dublin 2, Ireland.

${ }^{2}$ Centre for Research in Engineering Surface Technology (CREST), FOCAS, Dublin Institute of Technology, Kevin St, Dublin 8, Ireland.

${ }^{3}$ Plataforma Solar de Almería - CIEMAT, PO Box 22, 04200 Tabernas, Almería, Spain.

${ }^{4}$ Faculty of Engineering \& Physical Sciences, University of Surrey, Guildford, Surrey, GU2 7XH, United Kingdom

${ }^{\dagger}$ First Two authors (MB Fisher and DA Keane) had equal contribution

*Authors for correspondence: Phone: +353 (0)1 4022207; +353 (0)1 4027946 E-mail: kmcguigan@rcsi.ie; suresh.pillai@dit.ie 


\begin{abstract}
A novel class of photocatalytic coating capable of degrading bacterial and chemical contaminants in the presence of visible sunlight wavelengths was produced by depositing a stable photocatalytic $\mathrm{TiO}_{2}$ film on the internal lumen of glass bottles via a sol gel method. This coating was prepared in either undoped form or doped with nitrogen and/or copper to produce visible light-active $\mathrm{TiO}_{2}$ films which were annealed at 600 ${ }^{\circ} \mathrm{C}$ and were characterized by Raman, UV-Vis, and X-ray photoelectron spectroscopy. The presence of doped and undoped $\mathrm{TiO}_{2}$ films was found to accelerate the degradation of methylene blue in the presence of natural sunlight, while copper-doped $\mathrm{TiO}_{2}$ films were found to accelerate bacterial inactivation (of E. coli and E. faecalis) in the presence of natural sunlight.
\end{abstract}

KEYWORDS: Sunlight, visible light, Titanium Dioxide, Photocatalysis, Thin film, Emerging pollutants, SODIS, Disinfection, Bacterial deactivation, contamination, Visible light, Depollution, Anatase. 


\section{Introduction}

Contaminated drinking water contributes significantly to diarrheal illnesses in developing countries, which account for more than two million deaths per year, primarily among children under the age of five [1]. Contaminated water may also cause disease in developed countries, particularly among immunocompromised individuals [2]. There is thus great interest in affordable technologies capable of reducing the risk of waterborne diseases in developed and developing countries, particularly in settings where conventional drinking water distribution systems fail to eliminate waterborne pathogens. One technology that has found widespread application is solar water disinfection, or SODIS, which uses sunlight to inactivate microorganisms [3]. While many trials have demonstrated the efficacy and benefits of this technology, there is interest in new innovations that can enhance microbial inactivation while degrading chemical contaminants that may be present in drinking water.

Titanium dioxide $\left(\mathrm{TiO}_{2}\right)$ is a naturally-occurring mineral with optical and electronic properties that make it suitable for a range of applications in the areas of photovoltaics, sensors and photocatalysis [4-7]. Specifically, anatase-phase $\mathrm{TiO}_{2}$ has a band gap of $3.2 \mathrm{eV}$, and as a result is capable of absorbing photons of ultraviolet light $(<390 \mathrm{~nm})$ to create charge separation in the form of reducing electrons and strongly oxidizing "holes," which can react with water and other species in solution to form hydroxyl radicals, superoxide radical anions, and other reactive species $[4,8]$. Undoped $\mathrm{TiO}_{2}$ photocatalysts, on which much prior research has focused, show relatively high photo-reactivity and self-sterilisation properties under ultraviolet (UV) light. However, the development of photocatalysts with high quantum yields under visible light $(>400 \mathrm{~nm})$ is desired in order to harness the remainder of the solar spectrum to efficiently degrade chemical contaminants and inactivate pathogenic microorganisms.

Studies have demonstrated the ability of $\mathrm{TiO}_{2}$ to accelerate the sunlight-mediated inactivation of microorganisms [9] and the degradation of organic and inorganic contaminants [10-12]. Studies using suspended titania photocatalysts in water have typically demonstrated greater efficacy than studies using heterogeneous photocatalysts immobilized on substrates [13]. This may be primarily due to mass transfer limitations that reduce the efficacy of immobilized $\mathrm{TiO}_{2}$ photocatalysts in bulk solution [14]. However, 
suspended catalysts present logistical problems, since they must be removed from solution before the treated water can be used. Recent studies have demonstrated that a variety of dopants can modify the band gap of titanium dioxide photocatalysts, shifting the photocatalytic activity of the resulting materials into the visible range [15-17], while surface-modified and nanocomposite titania preparations exhibit similar activity [18]. Recently, it has been reported that the co-doping of metal and non-metal elements can result in increased visible light photocatalytic performance. [21]

While many previous studies used powdered $\mathrm{TiO}_{2}$ coatings, such coatings are not transparent and are often poorly adhered. Packing bottles with titania-coated supports is also not ideal for SODIS applications, because inserts reduce the effective volume and rarely inactivate indicator organisms [13]. The ideal configuration would be a transparent, well-adhered $\mathrm{TiO}_{2}$ coating on the inside of a reusable bottle, if such a coating could overcome mass transfer limitations. PET bottles are unsuitable, as they cannot withstand the high temperatures required to crystallize and sinter $\mathrm{TiO}_{2}$ thin films. By contrast, glass is transparent to visible and UVA wavelengths, is thermally stable up to $600^{\circ} \mathrm{C}$ (borosilicate), and $\mathrm{TiO}_{2}$ adheres to glass surfaces [19].

In this study, we sought to evaluate the ability of thin films of nitrogen- and copper-doped $\mathrm{TiO}_{2}$ to enhance the sunlight-mediated degradation of organic compounds and indicator microorganisms in water. Previous studies have reported on the applications of titanium dioxide species to the remediation of microbial [9] and chemical [10-12] contaminants, and have also characterized the behavior of titania particles doped with copper and other transition metals [21]. However, to our knowledge, this is the first attempt to characterize the ability of a self-adhered nitrogen- or copper-doped titania thin film to degrade chemical and microbial contaminants in water. 


\section{Materials and Methods}

\subsection{Materials and Reagents}

Glass beads, titanium isopropoxide (TIP), acetic acid, methylene blue, and urea were obtained from Sigma-Aldrich. Copper nitrate was obtained from BDH Chemicals. Copper chloride and copper sulfate were obtained from Fisher Scientific (Pittsburgh, PA). All chemicals were reagent grade and were used without further purification.

\subsection{Synthesis of $\mathrm{TiO}_{2}$ precasting sols}

An undoped titania sol was prepared in clean, dry glassware according to the procedure of Warrier et al. using acetic acid, titanium isopropoxide and water [20]. The hydrolysed sol (without modification) was used for coating borosilicate glass bottles (Schott) and microscope slides. The corresponding powder was obtained by drying the sol at $100{ }^{\circ} \mathrm{C}$ for 24 hours. Copper and nitrogen doping of the sols was achieved using copper nitrate and urea as dopant precursors [21]. In a typical experiment to produce nitrogendoped titania $\left(\mathrm{N}-\mathrm{TiO}_{2}\right)$, Urea $(0.177 \mathrm{~g})$ was dissolved in $150 \mathrm{ml}$ of deionised water. This solution was added to the TIP-acetic acid mixture to form a colourless transparent sol. Upon drying, the corresponding powder was white and developed a slight yellow hue after annealing at $600{ }^{\circ} \mathrm{C}$. $\mathrm{Cu}-\mathrm{TiO}_{2}$ was prepared as follows. Copper nitrate $(0.204 \mathrm{~g})$ was dissolved in $150 \mathrm{ml}$ of deionised water. This solution was added to the TIP-acetic acid mixture to form a light blue transparent sol. The corresponding powder was also light blue, which changed to a dark green [23] after annealing at $600{ }^{\circ} \mathrm{C}$. In a typical experiment $\mathrm{N}, \mathrm{Cu}$ $\mathrm{TiO}_{2}$ was synthesised as follows. Urea $(0.177 \mathrm{~g})$ and copper nitrate $(0.204 \mathrm{~g})$ were dissolved in $150 \mathrm{ml}$ deionised water. This solution was added to the TIP-acetic acid mixture to form a light blue transparent sol.

Glass slides were dip-coated and then air-dried by hanging vertically, allowing the sol to drain from the slide and dry slowly to form a $\mathrm{TiO}_{2}$ thin film. Glass bottles were coated by filling each bottle with the sol, emptying the bottle, and allowing it to dry at room temperature in an inverted position. Glass beads were coated by weighing a known quantity of the beads in a glass beaker and filling the beaker until the beads 
were completely immersed. The sol was then decanted from the beaker and the beads were dried at room temperature. The coatings were annealed in a furnace at $600{ }^{\circ} \mathrm{C}$ for 30 mins after the first coating and at $600{ }^{\circ} \mathrm{C}$ for 2 hours after the second coating. The heating rate was $10^{\circ} \mathrm{C} / \mathrm{min}$. The dip-coated glass microscope slides were annealed at $450{ }^{\circ} \mathrm{C}$ for 2 hours. After heat treatment, the glass-beads were washed thoroughly in isopropanol to remove any delaminated $\mathrm{TiO}_{2}$

\section{$2.3 \mathrm{TiO}_{2}$ Characterization}

X-ray photoelectron spectroscopy (XPS) analyses were performed on a Thermo VG Scientific Theta Probe spectrometer using monochromatic Alka radiation (photon energy $1486.6 \mathrm{eV}$ ), [22]

\subsection{Photocatalysis study}

The photocatalytic activity of the coated bottles was determined by methylene blue degradation in the presence natural sunlight. The methylene blue test is now widely accepted for the determination of the photocatalytic activity of surfaces (ISO 10678:2010). In the field study, 250-ml coated and uncoated bottles were filled with $10^{-5} \mathrm{M}$ methylene blue solution, capped, and placed horizontally on a concrete surface outdoors. Dye degradation was monitored by UV-vis spectroscopy $\left(\lambda_{\max }=664 \mathrm{~nm}\right)$. In all cases, the rate of degradation was assumed to obey pseudo-first order kinetics, and hence the rate constant for degradation, $\mathrm{k}$, was obtained from a first order regression of absorbance vs. time (Equation 1).

$$
\ln \left(\frac{A_{0}}{A}\right)=k t
$$

Where, $A_{0}$ is the initial absorbance, $A$ is the absorbance at time (t), and $k$ is the pseudo-first order rate constant.

2.5 Bacterial Inactivation Trials

Bacterial inactivation trials were performed in glass bottles filled with phosphate buffered saline $(\mathrm{pH} 7.4$, $50 \mathrm{mM}$ ) and exposed to natural sunlight. Bottles were exposed with no covering or covered with 
envelopes made from a commercial UV-blocking window film (3M Corporation, St. Paul, MN), which eliminated wavelengths below $400 \mathrm{~nm}$.

E. coli K12 MG1655 and Enterococcus faecalis 29181 were grown in LB broth to concentrations of $10^{9}$ colony forming units (CFU) per $\mathrm{mL}$, centrifuged, washed, and re-suspended in sterile PBS at concentrations of approximately $10^{6} \mathrm{CFU} / \mathrm{mL}$. These samples were then exposed to natural sunlight in glass bottles with or without $\mathrm{TiO}_{2}$ coatings.

Samples were enumerated by standard plate count techniques. Briefly, aliquots were serially-diluted into sterile PBS and plated on M. E. coli agar (E. coli) and Slanetz and Bartley medium (Enterococcus) via the drop plate technique. Plates were incubated at 37 and $35^{\circ} \mathrm{C}$, respectively, for $24 \mathrm{~h}$ prior to enumeration.

Laboratory bacterial inactivation trials were conducted using a 1000 W Diverging Beam, Xenon Arc Solar Simulating Lamp (Oriel Corp. Stratford, CT, USA) fitted with an Air Mass 1.0 solar filter designed to produce a spectrum similar to mid-day summer sunlight. Field trials were conducted at Plataforma Solar de Almeria (PSA) in southern Spain (37.5 $\mathrm{N}$ longitude $x 2.3^{\circ} \mathrm{W}$ latitude) using natural sunlight. Solar irradiance was measured using a Stellarnet BLK-R portable spectroradiometer (Stellarnet Inc., Tampa, FL, USA), and mean irradiance was approximately $450-500 \mathrm{~W} / \mathrm{m}^{2}$ for natural sunlight experiments.

\section{Results}

Glass microscope slides were coated to investigate whether well-adhered thin films of anatase-phase $\mathrm{TiO}_{2}$ could be formed. The coating was found to be well-adhered even before heat-treatment and the adhesion (BS EN ISO 2409:2007) was further improved after the film was annealed at $450{ }^{\circ} \mathrm{C}$. Raman spectroscopy was employed to confirm the presence and phase of the $\mathrm{TiO}_{2}$ thin film on glass slides [2325]. A Raman spectrum of a thin film annealed at $450^{\circ} \mathrm{C}$ clearly shows four bands located at 141,394 , 517 and $637 \mathrm{~cm}^{-1}$, characteristic of the anatase crystalline phase of $\mathrm{TiO}_{2}$. XPS studies were carried out to determine whether nitrogen and copper were successfully doped into the $\mathrm{TiO}_{2}$ thin films. Both doped and undoped powders and thin films on glass were characterized, and found to be identical except for extra 
peaks in the film due to silicon ( $\mathrm{Si} 2 \mathrm{p})$, calcium (Ca2p), and chloride (Cl2p), which were present in the glass slide. The characteristic peaks of titanium (Ti2p), oxygen (O1s), and carbon (C1s) were observed in all samples. Copper in the $(+2)$ oxidation state $\left(\mathrm{Cu}_{2} \mathrm{p}_{3 / 2}\right)$, was readily observed in all Cu-containing samples, showing that copper was successfully doped into the photocatalyst. In contrast, $\mathrm{N}$ was found in such small quantities that it is difficult to determine whether it behaved as a dopant or as an adventitious contaminant.

\subsection{1}

Under sunny, clear conditions, uncoated and coated bottles were filled with MB solution and exposed outdoors in sunlight for six hours. The experimental results are shown in Figure 1. The coated bottles produced increased degradation of the dye compared to the uncoated bottles, as shown by UV-vis measurements at $664 \mathrm{~nm}$ (Figure 1 (a) and (b)). After six hours, complete decolouration was observed in the coated bottles, whereas visible colour remained in the uncoated bottles. The kinetic data again showed a dye degradation rate in the coated bottles that was just over twice that observed in the uncoated containers, as shown in Figure 1 (d). Significantly, the doped $\mathrm{TiO}_{2}$ coated bottles showed no increase in MB degradation over undoped titania.

\subsection{Bacterial inactivation}

\subsubsection{Solar irradiation}

E. coli and Enterococcus faecalis bacteria were rapidly inactivated by natural sunlight in the presence and absence of titania photocatalysts. Undoped titania slightly accelerated the inactivation of $E$. coli, while Enterococcus was inactivated at approximately the same rate under both conditions (Figure $2 \mathrm{a}, \mathrm{b}$ ). Both species were inactivated most rapidly in the presence of $\mathrm{TiO}_{2}$ doped with copper (doping ratio $=1 \%$ ), and most slowly in the presence of $\mathrm{N}$-doped $\mathrm{TiO}_{2}$ (with no $\mathrm{Cu}$ ). Figure 2(a) shows that the last culturable $E$. coli sample was taken from the $\mathrm{Cu}(1 \%)$ bottle at the 1 hour time point. All subsequent samples taken from this container were below the detection limit (1 CFU/100ml.) and consequently not plotted. This total inactivation occurs 20 minutes earlier than was observed for all the other containers in this experiment. In 
the presence of undoped titania and $\mathrm{TiO}_{2}$ doped with $\mathrm{N}(3.5 \%)$ and $\mathrm{N} / \mathrm{Cu}(3.5 \% / 1 \%)$, both bacteria were inactivated at approximately the same intermediate rate as in the absence of a photocatalyst (Figure 3a, b). No E. coli or Enterococcus inactivation was observed in dark control bottles.

\subsubsection{Natural sunlight without UV}

E. coli and Enterococcus were also inactivated by natural sunlight in the absence of UV wavelengths, albeit more slowly (Figure $2 \mathrm{c}$, d;). Undoped and $\mathrm{N}$-doped (with no $\mathrm{Cu}$ ) $\mathrm{TiO}_{2}$ did not accelerate the inactivation of either organism. E. coli appeared to be inactivated slightly more rapidly in the presence of Cu-doped $\mathrm{TiO}_{2}$ than in the presence of undoped $\mathrm{TiO}_{2}$ or no photocatalyst. No difference was observed for Enterococcus faecalis (Figure 2d) between inactivation in the presence of $\mathrm{Cu}$-doped $\mathrm{TiO}_{2}$ vs. no catalyst, while inactivation appeared to proceed slightly more slowly in the presence of undoped and $\mathrm{N}$-doped $\mathrm{TiO}_{2}$ (with no $\mathrm{Cu}$ ). No E. coli or Enterococcus faecalis inactivation was observed in any dark control bottles.

\subsubsection{VLAT-coated beads}

E. coli and Enterococcus were inactivated by natural sunlight at the same rate in the presence of uncoated and undoped $\mathrm{TiO}_{2}$-coated 3-mm glass beads. Inactivation proceeded slightly more rapidly in the presence of $\mathrm{Cu} / \mathrm{N}$-doped $\mathrm{TiO}_{2}$ glass beads (Figure $3 \mathrm{a}, \mathrm{b}$ ). In the absence of UV wavelengths, the enhancement produced by the $\mathrm{Cu} / \mathrm{N}$-doped beads was more pronounced for both organisms, while $E$. coli were inactivated more slowly in the presence of undoped $\mathrm{TiO}_{2}$-coated beads than in the presence of uncoated beads, whereas Enterococci were inactivated at the same rate under the latter two conditions (Figure $3 \mathrm{c}, \mathrm{d}$ ). No E. coli or Enterococcus inactivation was observed in any dark control bottles.

\section{Discussion}

The more rapid decolouration of methylene blue in the presence of titania films is consistent with the widely reported photocatalytic properties of $\mathrm{TiO}_{2}$. In presence of the solar light irradiation, methylene blue can be degraded by three different routes a) photolysis or photo-bleaching 2) photosensitization and 3) photocatalysis. Methylene blue can undergo photolytic degradation without a photocatalyst; irradiated 
methylene blue forms an excited state and can transfer electrons to molecular oxygen, producing superoxide ions, which contribute to the degradation of the dye. In the presence of a semiconductor photocatalyst, photosensitized degradation occurs when excited electrons from irradiated dye molecules move to the conduction band of titania photocatalysts and then react with oxygen to form superoxide anions, which in turn degrade the dye. The photosensitization reaction is generally independent of the dopants or band gap of the material used, as the reaction is directly occurring at the conduction band. Briefly: the absorption of a photon with energy greater than the band gap of the semiconductor excites a valence band electron to the conduction band $\left(e_{C B}^{-}\right)$, generating a positive hole in the valence band $\left(h^{+}{ }_{\mathrm{VB}}\right)$.

$$
\mathrm{TiO}_{2}+\mathrm{h} v \rightarrow \mathrm{h}^{+}{ }_{\mathrm{VB}}+\mathrm{e}_{\mathrm{CB}}^{-}
$$

Positive holes generated by light become trapped by surface-adsorbed $\mathrm{H}_{2} \mathrm{O}$, which is oxidized by $\mathrm{h}^{+} \mathrm{vB}$, producing $\mathrm{H}^{+}$and ${ }^{\circ} \mathrm{OH}$ radicals.

$$
\begin{aligned}
& \mathrm{H}_{2} \mathrm{O}+\mathrm{h}^{+}{ }_{\mathrm{VB}} \rightarrow{ }^{-} \mathrm{OH}+\mathrm{H}^{+} \\
& \mathrm{O}_{2}+\mathrm{e}_{\mathrm{CB}}^{-} \rightarrow \mathrm{O}_{2}^{-} \cdot
\end{aligned}
$$

Hydroxyl radicals and superoxide anions produced by the photocatalytic process (equations 1 to 3 ) oxidize the majority of organic compounds until complete mineralization is achieved [4]. In addition to the super oxide anions, hydroxyl radicals, singlet oxygen will also be formed). Oxygen has two singlet excited states above the triplet ground ones [4]. It was reported that the photocatalytic inactivation of $E$. coli did not involve the hydroxyl radical production [9]. The hole, produced by the visible light irradiation, in the mid-gap levels (induced by doping) will not have the sufficient redox potential to oxidize organic molecules such as methylene blue. The formation of singlet oxygen, a less oxidative, reactive oxidation species was reported to be responsible for the bacterial decontamination [9].

Hermann et al suggested the decomposition of methylene blue leads to the conversion of organic carbon into harmless formation of gaseous $\mathrm{CO}_{2}$ and that of nitrogen and sulfur heteroatoms into inorganic ions. For example the proposed full degradation of methylene blue can be explained as in equation (4). 
Photocatalysis $\left(\mathrm{TiO}_{2}\right)$

$\mathrm{C}_{16} \mathrm{H}_{18} \mathrm{~N}_{3} \mathrm{SCl}+25.5 \mathrm{O}_{2}$

$16 \mathrm{CO}_{2}+6 \mathrm{H}_{2} \mathrm{O}+\mathrm{HCl}+\mathrm{H}_{2} \mathrm{SO}_{4}$

$+3 \mathrm{HNO}_{3}$

The enhanced inactivation of E. coli and Enterococcus faecalis in the presence of Cu-doped titania may be due to the visible light activity of this photocatalyst, to the anti-microbial properties of copper atoms at exposed surfaces, or to other attributes of the material. It is interesting to note that while $1 \%$ Cu enhanced bacterial inactivation, $1 \% \mathrm{Cu}+3.5 \% \mathrm{~N}$ did not, perhaps because the $1 \% \mathrm{Cu}$-doped catalyst showed increased visible light absorption compared to the co-doped 1\% Cu/3.5\% N-doped catalyst (Figure 4). This suggests that the co-doped catalysts in this study were not optimized, and that $\mathrm{N}$ atoms in the lattice may have acted as recombination centers for photogenerated electrons and holes. This is similar to the findings of Song et al. [21], who observed decreased photocatalytic activity (dye degradation) when doping levels were above or below the optimal ratio.

While Cu-doped $\mathrm{TiO}_{2}$ films accelerated $E$. coli inactivation in the absence of UV wavelengths, implying visible-light activity, N-doped films either did not exhibit such activity or else this activity was outweighed by other effects that reduced observed bacterial inactivation rates.

The rapid inactivation of E. coli and Enterococcus faecalis in the presence of doped and undoped titaniacoated beads may be due to the fact that, unlike in coated bottles, light absorption occurred on the surface of the catalyst in contact with the media. Another contributing factor may be the increased surface-area-to-volume ratio of the glass bead substrate relative to coated bottles, and to the consequently shorter mean distance between target microorganisms and illuminated photocatalytic surfaces. The observation that $\mathrm{Cu} / \mathrm{N}$-doped $\mathrm{TiO}_{2}$ accelerated inactivation when coated on glass beads but not when coated on the internal surface of glass bottles may also indicate that any reactive species produced at $\mathrm{Cu} / \mathrm{N}$-doped photocatalytic surfaces are short-lived and can only diffuse short distances (on the order of $\mu \mathrm{m}$ ), and that bacterial inactivation by such species may thus be transport-limited. $\mathrm{H}_{2} \mathrm{O}_{2}$ and $\mathrm{O}_{2}{ }^{-}$are important reactive oxygen species that might plausibly have a mean diffusion distances on this 
length scale [30]. Bacterial cells may also adhere to catalytic surfaces, magnifying the effects of shortlived radical species [31]. The observation that $\mathrm{Cu} / \mathrm{N}$-doped $\mathrm{TiO}_{2}$-coated beads accelerated $E$. coli inactivation in the absence of UV wavelengths, while the same photocatalyst coated on the inside of a glass bottle did not, suggests that this coating may possess significant visible light activity with the capacity to inactivate microorganisms at short diffusion distances.

Under static conditions (without mixing) over several hours, there is a possibility that microorganisms settle to the bottom of the bottles. In the glass beads, this settlement would take place over more $\mathrm{TiO}_{2}$ surface, favouring the inactivation process. However the authors have previously searched for this microbial settling effect within solar disinfection bottles and have found no evidence to support its existence. The absence of settling probably results from convective mixing established within the liquid during exposure.

By contrast, the enhanced inactivation of bacteria in $250-\mathrm{mL}$ bottles coated with Cu-doped titania may indicate a greater diffusion distance of one or more reactive species produced by this photocatalyst. Based on the observed efficacy of bottles coated with titania doped only with $1 \%$ copper, future studies of glass beads and other media coated with this photocatalyst are warranted.

Standard borosilicate glass is opaque to UVB but has higher UVA transmittance than PET plastic. The lower UVA transmittance of PET is balanced by the thinner wall thickness in the plastic bottles such that overall UVA transmittance of glass and PET bottles is similar [32]. Since the baseline rate of methylene blue degradation by natural sunlight is relatively low, the photocatalytic degradation of this compound was observed and quantified with reasonable accuracy during these trials. However, the high baseline inactivation rates of bacterial indicators in the presence of solar UV light makes it more difficult to observe small enhancement effects due to photocatalytic coatings, particularly to the extent that these coatings may screen germicidal wavelengths while simultaneously damaging bacteria via photocatalytic mechanisms. Thus, coatings which did not significantly enhance bacterial inactivation rates in this study may nonetheless possess some antimicrobial efficacy that was not quantified in this work. It should also 
be noted that results of anti-bacterial studies and photocatalysis studies don't complement each other. After Ryu et als work [33], it is now accepted that photocatalytic activities are roughly correlated only with respect to the degradation of structurally related compounds. Thus, the the $\mathrm{Cu}$ - and $\mathrm{Cu} / \mathrm{N}$-doped titania thin films studied in this trial appear to be the most promising candidates for future study and water treatment applications. .

\section{Conclusion}

In this work, robust, transparent titania thin films were deposited by a sol-gel method. Bottles coated with these films and annealed at $600{ }^{\circ} \mathrm{C}$ were found to degrade methylene blue more rapidly than uncoated bottles in field trials. However, N-doped titania photocatalytic coatings did not show increased MB degradation rates compared to undoped titania. By contrast, $\mathrm{Cu}$ and $\mathrm{N}$-doped-doped photocatalystcoated bottles appeared to demonstrate improved bacterial photoinactivation relative to undoped titania, and these effects appeared to persist in the absence of UV wavelengths.

$\mathrm{Cu}$ - and $\mathrm{Cu} / \mathrm{N}$-doped titania thin films showed potential for the degradation of microbiological and chemical contaminants in the presence of visible light or sunlight in these trials. The former appeared to accelerate the inactivation of indicator bacteria when coated on the inside of glass bottles, while the latter only proved effective when coated on 3-mm glass beads. Applications of such thin film VLAT photocatalysts to the treatment and remediation of drinking water, groundwater, and wastewater, as well as to clinical and emergency settings, appear to merit further exploration and study.

\section{Acknowledgements}

The authors would like to thank Enterprise Ireland (Grant Number PC/2009/0014) for research funding. Financial support by the Access to Research Infrastructures (to PSA facilities, Almeria) activity FP7SFERA Grant No 228296) is also gratefully acknowledged. 


\section{FIGURE CAPTIONS}

Figure 1. Photodegradation results in natural sunlight at PSA. (a) Absorption spectra of dye degradation as a function of time in an uncoated bottle (b) Absorption spectra of dye degradation as a function of time in a $\mathrm{TiO}_{2}$-coated bottle (c) Photograph of uncoated and $\mathrm{TiO}_{2}$-coated bottles containing dye after 6 hours in natural sunlight (d) Kinetic data of photodegradation in uncoated and $\mathrm{TiO}_{2}$-coated bottles

Figure 2. Inactivation of E. coli and Enterococcus faecalis by natural sunlight in glass bottles with or without UV-blocking film in the presence and absence of undoped $\mathrm{TiO}_{2}$ thin films and films doped with $\mathrm{N}$ (with no $\mathrm{Cu}$ ) or $1 \% \mathrm{Cu}$. (a) E. coli, sunlight (b) Enterococcus, sunlight (c) E. coli, no UV (d) Enterococcus, no UV.

Figure 3, Inactivation of E. coli and Enterococcus faecalis by natural sunlight with or without UV-blocking film in the presence and absence of 3-mm glass beads coated with undoped $\mathrm{TiO}_{2}$ thin films and films doped with $1 \% \mathrm{Cu} / 3.5 \%$ N. (a) E. coli, sunlight (b) Enterococcus, sunlight (c) E. coli, no UV (d) Enterococcus, no UV 


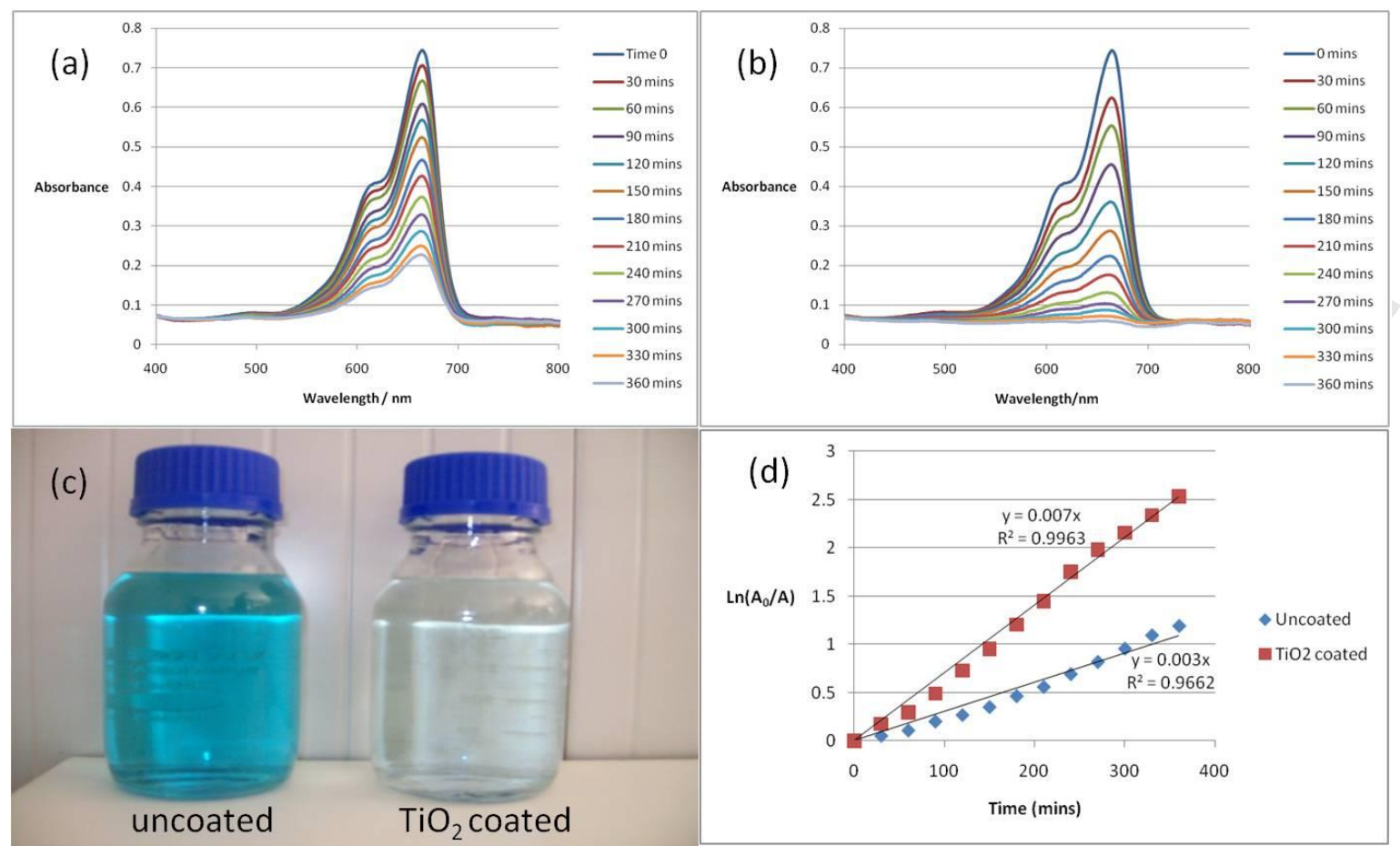

Figure 1. 
(a)

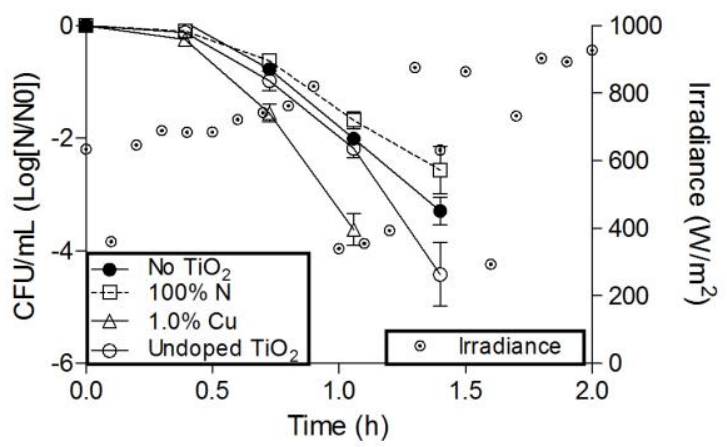

(c)

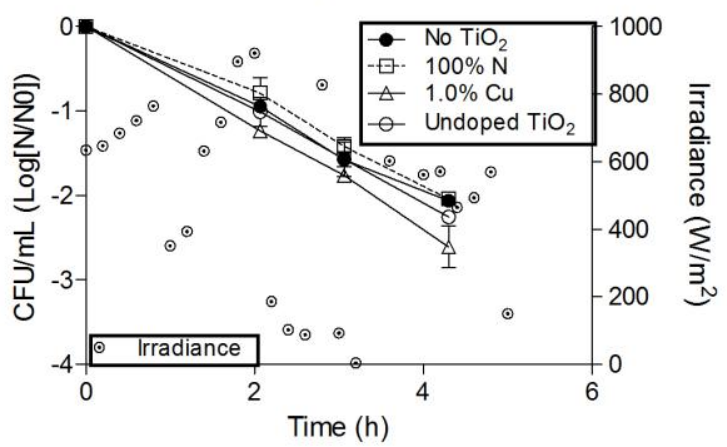

(b)

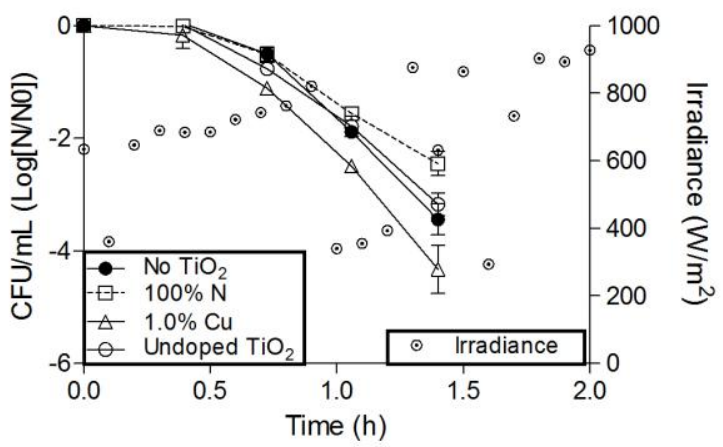

(d)

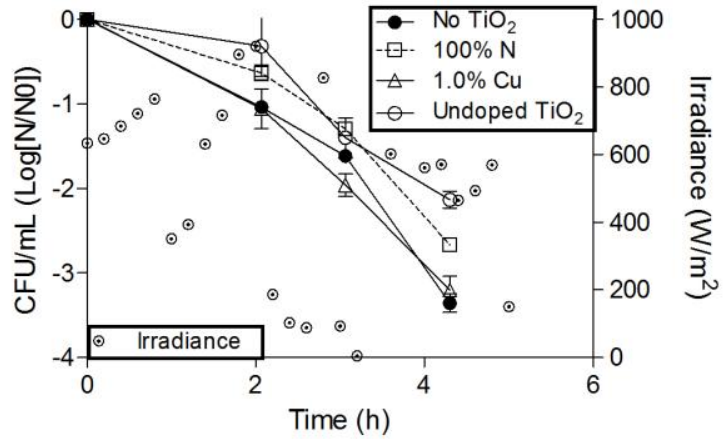

Figure 2. 
(a)

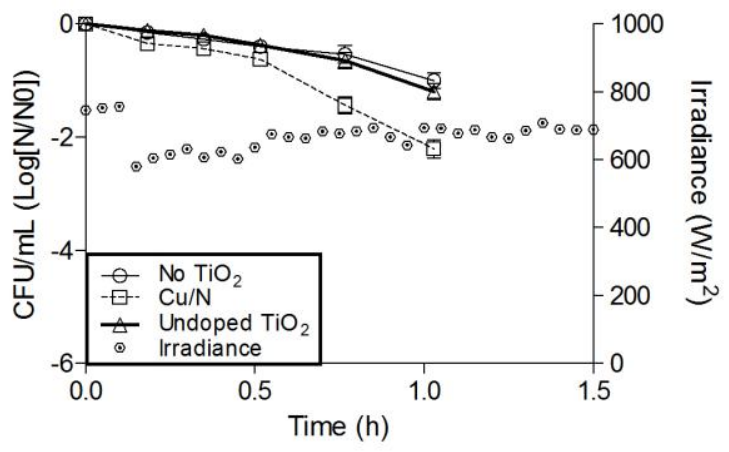

(c)

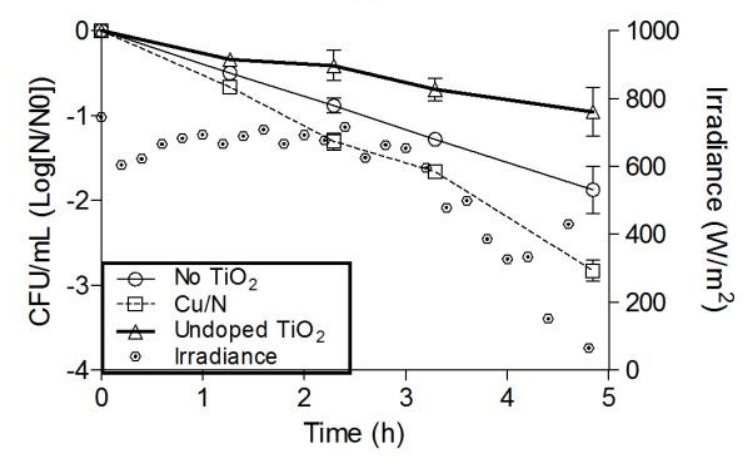

(b)

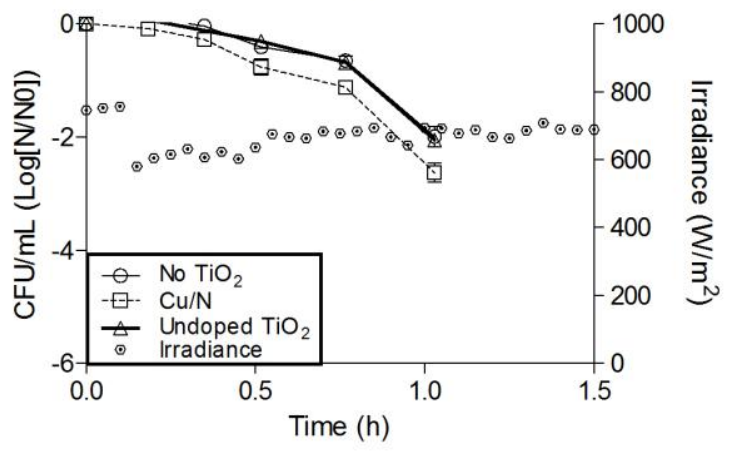

(d)

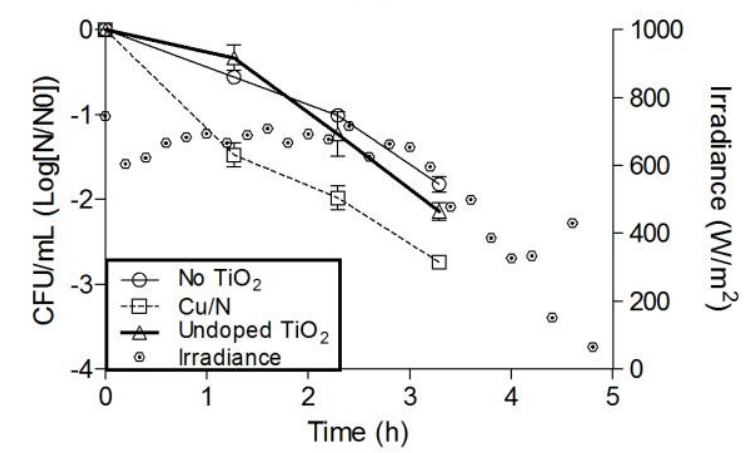

Figure 3. 


\section{References}

[1] WHO, Global health risks: mortality and burden of disease attributable to selected major risks, World Health Organization, 2009.

[2] K.A. Reynolds, K.D. Mena, C.P. Gerba, Risk of Waterborne Illness Via Drinking Water in the United States, Reviews of Environmental Contamination and Toxicology, in: D.M. Whitacre (Ed.), Springer New York, 2008, pp. 117-158.

[3] M. du Preez, K.G. McGuigan, R.M. Conroy, Environ. Sci. Techn. 44,(2010), 8744-9

[4] M. Pelaez, N. T. Nolan, S. C. Pillai, M. K. Seery, P. Falaras, A. G. Kontos, P. S.M. Dunlop, J. W.J. Hamilton, J. Byrne, K. O’Shea, M. H. Entezari, D. D. Dionysiou, Applied Catalysis B 125 (2012) 331- 349

[5] M.R. Hoffmann, S.T. Martin, W. Choi, D.W. Bahnemann, Chem. Rev., 95 (1995) 69-96.

[6] A. Mills, S.-K. Lee, , J. Photochem. Photobiol. A: Chem., 152 (2002) 233-247.

[7] A. Fujishima, K. Honda, , Nature, 238 (1972) 37-38.

[8] U. Diebold, Surf. Sci. Rep. 48 (2003) 53-229.

[9] J.A. Rengifo-Herrera, C. Pulgarin, Solar Energy 84 (2010) 37-43.

[10] H. Choi, E. Stathatos, D.D. Dionysiou, Applied Catalysis B 63 (2006) 60-67.

[11] C. Han, M. Pelaez, V. Likodimos, A.G. Kontos, P. Falaras, K. O'Shea, D.D. Dionysiou, Applied Catalysis B 107 (2011) 77-87

[12] J. Aguado, R. van Grieken, M.J. López-Muñoz, J. Marugán Catal. Today, 75 (2002) 95-102.

[13] R. van Grieken, J. Marugán, C. Sordo, C. Pablos, Catal. Today, 144 (2009) 48-54.

[14] R.W. Matthews, Water Res., 20 (1986) 569-578.

[15] R. Asahi, T. Morikawa, T. Ohwaki, K. Aoki, Y. Taga, Science, 293 (2001) 269-271.

[16] J. Ananpattarachai, P. Kajitvichyanukul, S. Seraphin, J. Haz. Mater. 168 (2009) 253-261. 
[17] N.T. Nolan, D.W. Synnott, M.K. Seery, S.J. Hinder, A. Van Wassenhoven, S.C. Pillai, J. Haz. Mater., 211- 212 (2012) 88-94

[18] T. Tachikawa, M. Fujitsuka, T. Majima, , J. Phys. Chem. C, 111 (2007) 5259-5275.

[19] R.L. Pozzo, M.A. Baltanas, A.E. Cassano, Catal. Today, 39 (1997) 219-231.

[20] S. R. Kumar, S.C. Pillai, U.S. Hareesh, P. Mukundan, K.G.K. Warrier, Mater. Lett., 43 286-290.

[21] K. Song, J. Zhou, J. Bao, Y. Feng, J. Am. Ceram. Soc., 91 (2008) 1369-1371.

[22] S.C. Pillai, P. Periyat, R. George, D.E. McCormack, M.K. Seery, H. Hayden, J. Colreavy, D. Corr,

S.J. Hinder, J. Phys. Chem. C, 111 (2007) 1605-1611.

[23] D. Bersani, G. Antonioli, P.P. Lottici, T. Lopez, , J. Non-Crystal. Solids, 232-234 (1998) 175-181.

[24] N.T. Nolan, M.K. Seery, S.C. Pillai, J. Phys. Chem. C, 113 (2009) 16151-16157.

[25] G. Socrates, Infrared and Raman Characteristic Group Frequencies, Tables and Charts, John Wiley \& Sons Ltd., Chichester, UK, 2001.

[30] Y. Kikuchi, K. Sunada, T. lyoda, K. Hashimoto, A. Fujishima, J. Photochem. Photobiol. A: Chem., 106 (1997) 51-56.

[31] Y. Horie, M. Taya, S. Tone, J. Chem. Eng. Jpn., 31 (1998) 922-929.

[32] E. Ubomba-Jaswa, P. Fernández-Ibáñez, C. Navntoft, M.I. Polo-López, K.G. McGuigan. J Chem Technol Biotechnol 85, 2010, 1028-1037.

[32] J. Ryu, W. Choi, Environ. Sci. Technol., 42 (2008) 294-300. 
Graphical abstract

Nitrogen and Copper doped sun light active $\mathrm{TiO}_{2}$ photocatalysts for water decontamination

Mike B. Fisher, Donal A. Keane, Pilar Fernández-lbáñez, John Colreavy, Steven J. Hinder, Kevin G. McGuigan, ${ }^{\star}$ Suresh C. Pillai ${ }^{\star}$

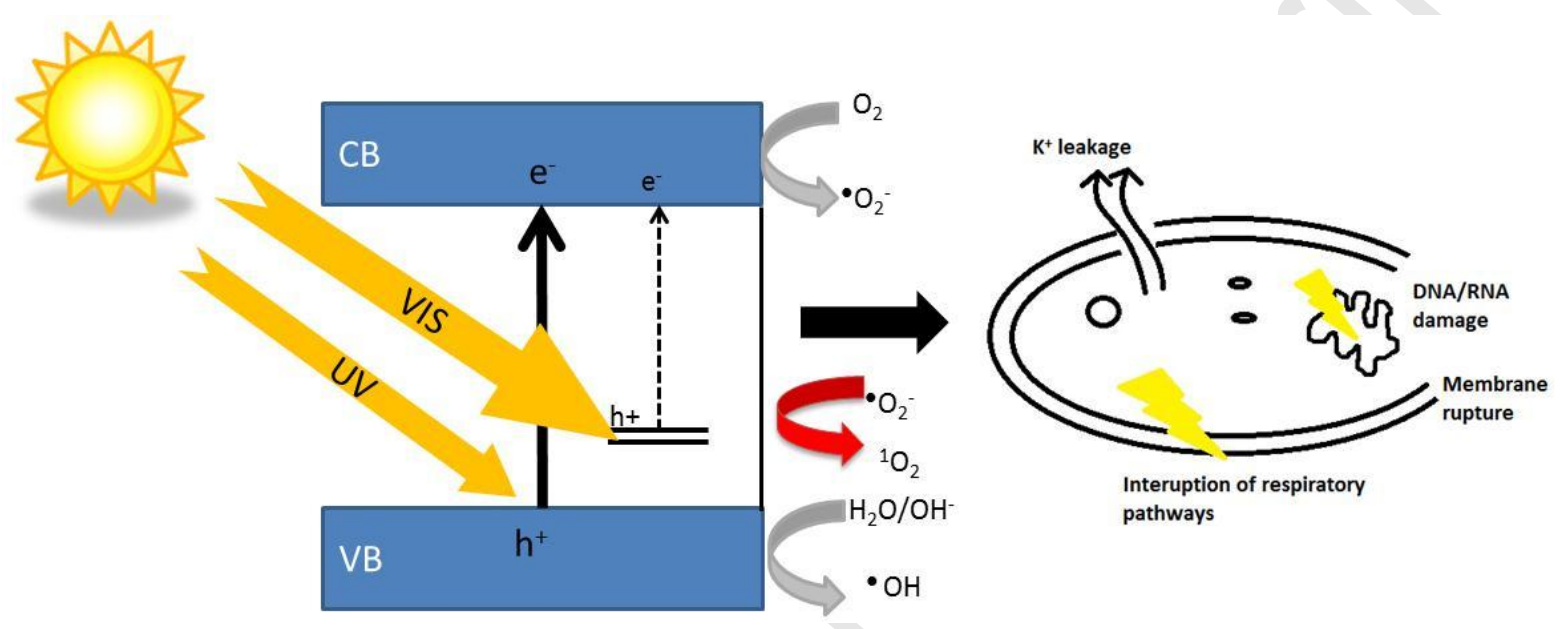

Schematic diagram of bacterial decontamination using visible light active catalyst 


\section{Highlights}

- A stable photocatalytic sun-light-active $\mathrm{TiO}_{2}$ (VLAT) coating has been developed.

- Enhanced photocatalytic activity of coated bottles was observed.

- Visible light activated accelerated the degradation of methylene blue under natural sunlight.

- Doped $\mathrm{TiO}_{2}$ films accelerated bacterial (e.g. E. Coli) inactivation under natural sunlight. 